\title{
The Hopeful Journey Towards Successful Tailoring of Water (In)Soluble Cobalt Analogues As Potential Water Splitting Catalysts.
}

\author{
Orbett T. Alexander, ${ }^{1 *}$ Roger Alberto ${ }^{2}$ and Andreas Roodt ${ }^{1}$ \\ ${ }^{1}$ Dept. of Chemistry, University of the Free State, Bloemfontein 9300, South Africa, \\ ${ }^{2}$ Dept. of Chemistry, University of Zürich, Winterthurerstrasse 190, Zürich, Switzerland.
}

AlexanderO@ufs.ac.za

The topic of renewable energies is vastly received as an $\mathrm{x}$-factor towards our energy problems in this modern world times. This notion holds tight following the current global outcry of dilapidating fossil fuels. The science fraternity continually aims at tabling innovative strategies towards engineering renewable energy sources. This transcends to efforts of making chemical fuels which are easily storable using solar energy.

Water reduction catalysts (WRCs), as widely known, are currently used for the splitting of water to $\mathrm{H}_{2}$ and $\mathrm{O}_{2}$. The hydrogen $\left(\mathrm{H}_{2}\right)$ generated, is eyed as a prominent potential fuel source. These catalysts are often tailored with different transition metal elements somewhat coupled with effective macro-cyclic organic scaffolds [1]; as suitable approach to store energy at times of reduced power supply by harnessing solar energy [2,3]. This renowned WRC science was preceded by the prominent scientific stun of the ruthenium(III) complex $\left\{\left[\mathrm{Ru}^{\mathrm{III}}(\mathrm{byp})_{3}\right]^{3+}\right\}$, as a photo-synthesizer [4]. Interestingly, different other light harvesting moieties are lately being considered, exhibiting greater photo-stability, longevity and rigidity as elemental prerequisites [5], many of whom are based on polypyridyl entities.
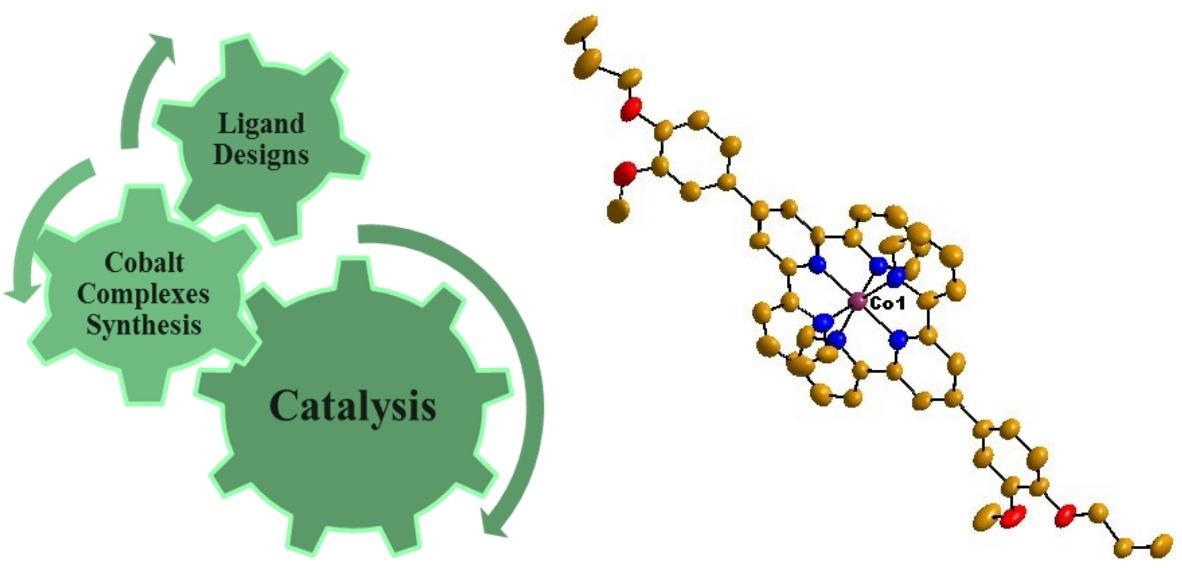

Figure 1: a)Idealized cog-wheel value chain towards successful engineering of WRCs. b) Homoleptic bis-coordinated cobalt complex.

In this presentation we discuss aspects of the ligand design strategy and cobalt coordination chemistry as exhibited in the value chain in the scheme just above. X-ray crystallographically characterised structures will be used to discuss different relative geometric preferences and characteristics of the respective analogues.

1. Joliat-Wick, E., Weder, N., Klose, D., Bachmann, C., Spingler, B., Probst, B. \& Alberto, R. (2018). Inorg. Chem., 57, 1651.

2. Guttentag, M., Rodenberg, A., Bachmann, C., Senn, A., Hamm, P. \& Alberto, R. (2013). Dalton Trans., $42,334$.

3. Joliat-Wick, E., Schnidrig, S., Probst, B., Bachmann, C., Spingler, B., Baldridge, K.K., Von Rohr F., Schilling, A. Alberto, R., (2016). Dalton Trans., 45, 1737.

4. (a) Kiwi, J., Gratzel, M. (1979). Nature, 285, 657. (b) Kiwi, J., Gratzel, M. (1979). J. Am. Chem. Soc., 101 7214. [5] (a) Alexander, O.T., Kroon, R.E., Brink, A. \& Visser, H.G. (2019). Dalton Trans. 48, 16074. (b) Kefalidi, C. Koutsouri, E., Marchiò, L.,A. Efstathiadou, S. Mitsopoulou, C.A. (2016). Polyhedron, 110, 157.

Keywords: Water-Reduction-Catalysts (WRC); Photo-Catalysis; Cobalt; Coordination Chemistry. 